\title{
Muscle electrical activity during exercises with and without load executed on dry land and in an aquatic environment
}

Indira Nayra Paz Santos, Izabela dos Santos Mendes, Mario Oliveira Lima, Alderico Rodrigues de Paula Junior, Andreza Ribeiro Simioni, Paulo Roberto Garcia Lucareli, Fernanda Pupio Silva Lima*

\begin{abstract}
Introduction: Muscle activity in the aquatic environment was investigated using electromyographic analyses. The physical properties of water and the resistance used may influence the response of the muscle during exercise. The objective of this study was to evaluate the electrical activity in water and on the floor during flexion and knee extension exercises with and without load and aimed at understanding the muscular response while performing resistance exercises in water. Methods: The sample consisted of 14 volunteers between 18 and 35 years old who were subjected to active exercises involving knee flexion and extension with and without load on the floor and in water. Electromyography was performed during the movement. Results: A significant increase was found in the electrical activity of the rectus femoris muscle during exercises on the floor. The biceps femoris muscle showed increased electromyographic activity when resistance was used. A significant increase was found in the electrical activity of the rectus femoris muscle compared with exercises with and without load and the moment of rest in immersion. The electrical activity of the rectus and biceps femoris muscles was reduced in exercises with load and without load in a therapy pool compared with on the floor. Conclusion: There was a reduction of the electromyographic activity in the aquatic environment compared with that on the ground, which could be attributed to the effects from hot water. Therefore, it is believed that resistance exercises can be performed early in a therapy pool, which will facilitate the prevention and treatment of musculoskeletal disorders.
\end{abstract}

Keywords: Electromyography, Hydrotherapy, Kinesiotherapy.

\section{Introduction}

Immersion treatment programs have been widely recommended because they provide many therapeutic benefits (Rahmann et al., 2009; Roper et al., 2013). The aquatic environment favors exercises that often would be implemented with difficulties on land (Batterham et al., 2011).

The physiological effects from immersion are related to the physical properties of water (Becker, 2009; Kisner and Colby, 2000), including the hydrodynamic principles, hydrostatics and thermodynamics, which are responsible for the differences in the musculoskeletal system response between exercises on land and in a therapy pool.

The muscular work in immersion is directly influenced by the thermodynamic property of water. The heat transfer ability of water is twenty-five times more efficient than that of air, and the heat transfer begins immediately after the immersion. Thus, a water temperature between $32^{\circ} \mathrm{C}$ and $33^{\circ} \mathrm{C}$ promotes muscle relaxation (Caromano and Nowotny, 2002).

The muscle endurance when performing floor exercises for therapeutic uses depends on the load and

*e-mail: fpupio@univap.br

Received: 07 July 2013 / Accepted: 15 January 2015 the action of gravity acting as the liquid medium. The resistance is determined by the hydrostatic pressure, viscosity, buoyancy of the equipment, size and surface area (Müller et al., 2005) and the speed of movement (Harrison et al., 1992; Müller et al., 2005). The viscosity and the hydrodynamic forces acting on the displacer require increased muscle torque compared with those on land (Castillo-Lozano and Cuesta-Vargas, 2013).

The assessment of muscle electrical activity can be performed either on the ground or in a liquid medium by means of electromyography, which allows the elucidation of muscle behavior in different situations in the context of the types of fiber and muscle contraction (Müller et al., 2005; Vodusek, 2007). The quantification of the electromyographic (EMG) activity in immersion is still considered a challenge due to the difficulty in setting the surface electrodes on the skin (Masumoto et al., 2004). When the EMG signal is properly carried out in the aquatic environment, the data integrity is maintained compared with data acquisition on the land (Castillo-Lozano and Cuesta-Vargas, 2013). 
A study by Pinto et al. (2010) showed no differences in the amplitude of the myoelectric signal for maximum strength exercises performed in water and on land. On the other hand, other studies found a reduction of the muscle electrical activity during exercises in the water compared with on the ground (Cuesta Vargas et al., 2013a; Fujisawa et al., 1998; Kelly et al., 2000; Masumoto et al., 2004; Pöyhönen et al., 1999). Müller et al. (2005) found that when the move occurred at full speed, there was increased electromyographic activity on land and in water. Cuesta-Vargas et al. (2013b) observed the most marked increase in the electrical activity of the trunk muscles in the aquatic environment compared with on land.

There is a need for further studies to quantify the electromyographic signal in the aquatic environment, especially as it concerns the comparison of muscle activity during movement performed with and without resistance from an external force. According to Escamilla et al. (1998), conducting exercises against a certain resistance has implications for rehabilitation, considering the possible existing mechanisms of injury if not carried out properly.

Therefore, this study aimed to evaluate and compare the muscle electrical activity during flexion and knee extension, performed on the ground and in water, with and without load use.

Our hypothesis was that the electromyographic activity during the exercises in the pool with heated water, considered therapeutic, would be lower than on land and that the exercises with resistance would promote increased electromyographic signals in these two environments.

The results of this study may contribute to an improved understanding of the muscle response when performing movements with load in water.

\section{Methods}

This was a cross-sectional study, developed in Sensory Motor Rehabilitation Engineering Laboratory and Sector hydrotherapy at the University of Vale do Paraíba (Univap), using a swimming pool with a depth of $1.40 \mathrm{~m}$ in the shallow end and a depth of $2.10 \mathrm{~m}$ in the deeper side. It is important to note that the latter had a mobile platform, which enabled individual adjustment for each individual. This study was approved by the Research Ethics Committee of the Univap, CAAE: 06708912.8.0000.5503.

The sample consisted of 14 adults (two males and twelve females), sedentary or who did not practice regular physical activity (less than three times a week), aged between 18 and 35 years.
The following exclusion criteria were considered:

- Individuals who had a history of pain, trauma and / or surgery o $n$ the knee joint;

- Clinical evidence of meniscal injury or ligament instability;

- Musculoskeletal disorders.

After the selection, all of the volunteers were invited to participate in two exercise protocols performed on the ground and in the heated pool with a minimum interval of 24 hours between each protocol. Data collection was performed only with the dominant member of each volunteer. All of the individuals signed the informed consent and were informed about the measures taken.

\section{Data collection}

The acquisition of the muscle electrical signal was performed by an eight channel electromyograph, EMG830 WF model (EMG System do Brasil Ltda ${ }^{\circledR}$, São José dos Campos/SP/Brasil), with the following technical characteristics: analog-to-digital conversion board (A/D) with 16-bit resolution; bipolar pre-amplified electrode with a differential gain of 20 times, totaling a final amplification of 1000 times; impedance $>10 \mathrm{MOhms}$, signal-to-noise ratio $<3 \mu$ Volts RMS; common mode rejection ratio $>120 \mathrm{~dB}$; analog band-pass filter of 20-500 Hz; sampling frequency set to $2 \mathrm{kHz}$ per channel.

Before attaching the electrodes, the removal of impurities was performed at the location with $70 \%$ ethanol, and the location was shaved to minimize the impedance of the electrode-skin interface. To collect the electromyographic signal $\mathrm{Ag} / \mathrm{AgCl}$ surface electrodes (Double ${ }^{\circledR}$ ) were used, with a contact diameter of $10 \mathrm{~mm}$ and a distance of $20 \mathrm{~mm}$ between centers.

The surface electrodes were positioned following surface electromyography protocol recommendations for the non-invasive assessment of muscles (SENIAM) under the rectus femoris muscle $(50 \%$ on the line from the anterior superior iliac spine to the top of the kneecap) and biceps femoris $(50 \%$ on the line between the ischial tuberosity and the tibial lateral epicondyle).

During the test in the therapeutic pool, we used surface electrodes with preamplifiers and a shielded coaxial extension cable for use in water. We used a waterproof occlusive tape (Tegaderm - 3M) and plastic wrap to avoid getting water on the electrodes. The reference electrode, preacher type, made of a metal plate was placed on the styloid process of the ulna.

\section{Experimental procedure}

The experimental procedure consisted of the application of two exercise protocols that were performed with the dominant member of each volunteer on land 
and in heated water, which were classified as protocol 1 and protocol 2, respectively, as mentioned below:

\section{Protocol 1}

- Heating: 5 min walk on a treadmill at a speed of $2.5 \mathrm{~km} / \mathrm{h}$;

- 5 min rest;

- EMG collection at rest in a sitting position for $20 \mathrm{~s}$, during which the knee joint was positioned at $90^{\circ}$ flexion.

- Active exercise of knee flexion and extension of the dominant leg without load in the sitting position on the ground during the $20 \mathrm{~s}$ EMG collection;

- 3 min rest;

- Active exercise of knee flexion and extension of the dominant leg in a seated position using a load of $2 \mathrm{kgf}$ positioned at the ankle during 20 s EMG collection;

- Stretching of the muscles of the lower limbs, emphasizing the quadriceps and hamstrings (3 repetitions of $15 \mathrm{~s}$ for each member).

The volunteers were instructed to carry out the maximum range of knee flexion and extension at a comfortable and harmonic speed.

\section{Protocol 2}

We carried out the same procedure as in Step 1; however, the pool heated at $34^{\circ} \mathrm{C}$, and the heating was performed on a mat, as described above. The level of immersion to the height of the xiphoid process in the sitting position of each individual was considered. The collection of the electromyographic signal was performed at home and during the exercises with and without load in the water as per the above protocols.

\section{Data analysis}

The electromyographic signals were saved in txt format and processed by EMGworks Analysis (Delsys ${ }^{\circledR}$ ) software. After obtaining the signals, we calculated the mean square value (root mean square - RMS) of each muscle contraction. Initially, the data were subjected to the D'Agostino normality test. It was found that all of the parameters satisfied the criteria of normality. The data were analyzed using a paired t-test for intra-group analysis and ANOVA with a post criterion Tukey test for intergroup analysis (land and therapy pool) using BioEstat software version 5.0 and considering a significance level of $5 \%$.

\section{Results}

To graphically present the RMS values of the electrical activity of the rectus femoris (Figure 1) and biceps femoris (Figure 2) in the different phases of
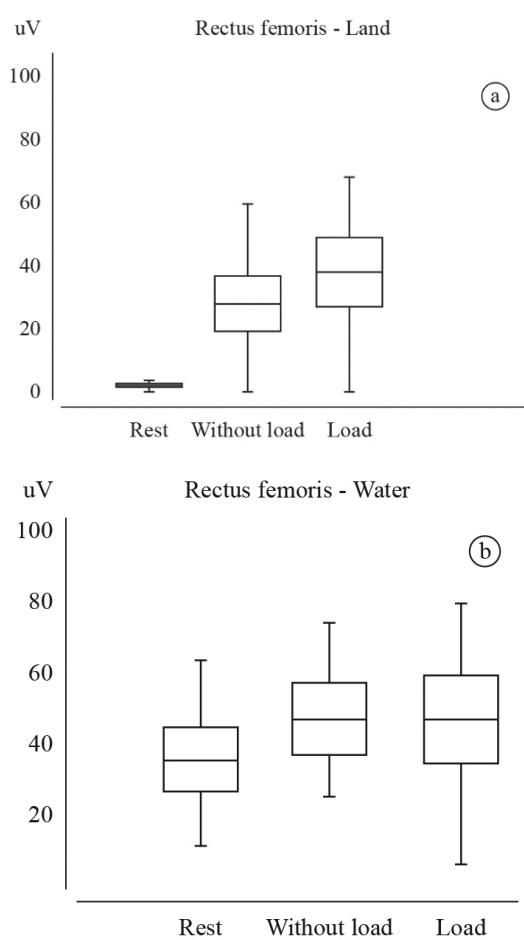

Figure 1. Box plots of the mean and two standard errors of the RMS values of the myoelectric signal of the rectus femoris (a) on the floor and (b) in the therapy pool.
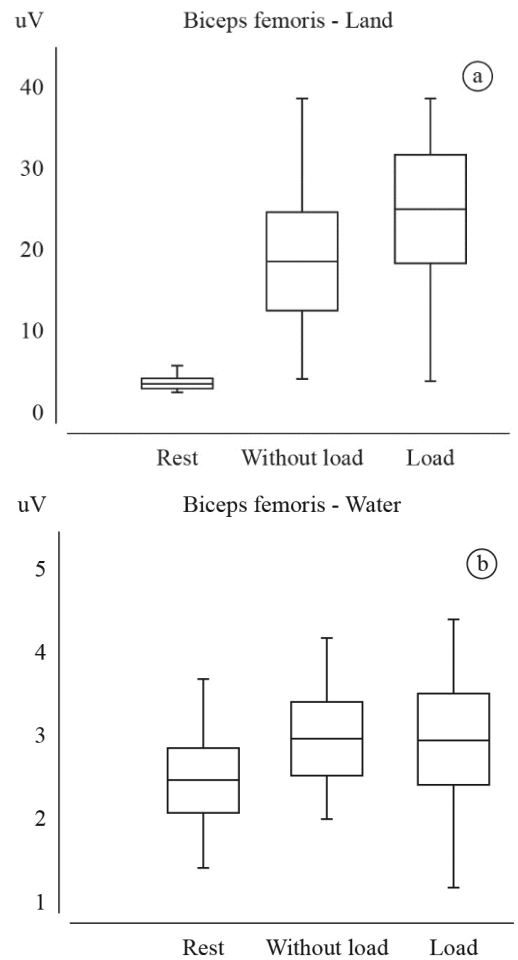

Figure 2. Box plots of the mean and two standard errors of the RMS values of the myoelectric signal of the biceps femoris (a) on the floor and (b) in the therapy pool. 
Table 1. Statistical results of electromyography during flexion and knee extension exercises with and without load performed on the floor and in the aquatic environment.

\begin{tabular}{lcc}
\hline & Electromyography - land & \\
\hline & Rectus femoris & Biceps femoris \\
\hline Rest x (flexion and extension without load*) & $(\uparrow) \mathbf{p}<\mathbf{0 . 0 1 *}$ & $\mathrm{ns}$ \\
Rest x (flexion and extension without load*) & $(\uparrow) \mathbf{p}<\mathbf{0 . 0 1 *}$ & $(\uparrow) \mathbf{p}<\mathbf{0 . 0 5 ^ { * }}$ \\
Flexion and extension: without load* $\mathrm{x}\left(\right.$ with load $\left.^{*}\right)$ & $(\uparrow)$ p $<0.05^{*}$ & $\mathrm{~ns}$ \\
\hline
\end{tabular}

Electromyography - Aquatic

\begin{tabular}{lcc}
\hline & Electromyography - Aquatic & \\
\hline & Rectus femoris & Biceps femoris \\
Rest x (flexion and extension without load*) & $(\uparrow) \mathbf{p}<\mathbf{0 . 0 1 *}$ & $\mathrm{ns}$ \\
Rest x (flexion and extension without load*) & $(\uparrow) \mathbf{p}<\mathbf{0 . 0 1 *}$ & $\mathrm{ns}$ \\
Flexion and extension: No load x With load & $\mathrm{ns}$ & $\mathrm{ns}$ \\
\hline
\end{tabular}

*Anova ( $\mathrm{p}<0.05)$; ns: not significant; $(\uparrow)$ : increase.

Table 2. Statistical results of electromyography during flexion and knee extension exercises with and without load comparing that on the floor with that in the aquatic environment.

\begin{tabular}{lcc}
\hline \multicolumn{1}{c}{ Electromyography } & Rectus femoris & Biceps femoris \\
\hline Land rest x (immersion rest*) & $(\downarrow) \mathbf{p}<\mathbf{0 . 0 0 1 *}$ & $(\downarrow) \mathbf{p}<\mathbf{0 . 0 0 1}$ \\
Flexion and extension: Land without load x (immersion without load*) & $(\downarrow) \mathbf{p}<\mathbf{0 . 0 0 1 *}$ & $(\downarrow) \mathbf{p}<\mathbf{0 . 0 0 1} *$ \\
Flexion and extension: Land with load x (immersion with load*) & $(\downarrow) \mathbf{p}<\mathbf{0 . 0 0 1 *}$ & $(\downarrow) \mathbf{p}<\mathbf{0 . 0 0 1 *}$ \\
\hline
\end{tabular}

*t-test $(\mathrm{p} \leq 0.05) ;(\downarrow)$ : decrease.

the protocol, we used the box plot average and two standard errors.

In this study, there was a significant increase in electrical activity of the rectus femoris muscle performed on the ground with and without load compared with the myoelectric signal collected at rest. There was a significant increase in the electrical activity of the rectus femoris muscle analyzed with and without load.

Regarding the biceps femoris muscle, a significant increase was observed when comparing the EMG activity at rest with that with loaded exercise; however, the EMG activity was not significant between rest and movement without load.

During the time in immersion, a significant increase was observed for only the electrical activity of the rectus femoris muscle during movements with and without load for the resting phase. In Table 1, the results obtained after statistical analysis are demonstrated.

There was a significant reduction of the electrical activity of the rectus femoris and biceps femoris at rest with and without load in the therapy pool compared with on land (Table 2).

\section{Discussion}

The maintenance and / or improvement of muscle performance are the main objectives set out in the development of exercise programs directed to people with or without changes in the musculoskeletal system.
In this study, we evaluated the muscle electrical activity during flexion and knee extension on land and in the aquatic environment. All of the subjects were instructed to perform the movements at a comfortable and harmonic speed according to procedures adopted in the study by Cardoso and Sousa (2003).

Considering the exercises performed on the ground, there was an increase in the electrical activity of the biceps femoris only compared with the movements performed with load for the resting phase. However, the rectus femoris muscle showed a significantly increased myoelectric signal with load compared with the no-load exercises and both movements relative to the time of rest. This result was justified considering that the knee extension movement was carried out with equipment resistance and was held against gravity. According to Devereux et al. (2005), in a terrestrial environment, movements made in favor of gravity required less force production, thus facilitating muscle contraction. However, the movements performed in the direction opposite to gravity had a higher resistance.

During the movements performed in immersion, there was a significant increase in the electric signal of the rectus femoris muscle with and without the use of load in comparison with the resting phase. The biceps femoris muscle showed an increased myoelectric signal; however, it was not significant. This increase could be attributed to the action of the hydrostatic pressure and the viscosity of the water, in addition to the additional resistance resulting from the load use. In addition, when the member moves in 
the aquatic environment, it is subjected to drag forces and turbulence (Becker, 2009)

By comparing the data for the movements performed in water and on land, there was a reduction in the electrical activity of the rectus and biceps femoris with and without load in the aquatic environment. These results were consistent with studies conducted by Sugajima et al. (1996) and Devereux et al. (2005), who found that in water, there was less force production compared with the terrestrial environment due to the buoyant force, which acts in the opposite direction to gravity and reduces the apparent weight (hydrostatic weight). Pöyhönen et al. (1999) found a significant reduction in the amplitude of the electromyographic signal during submaximal and maximal contractions of the knee extensor muscles in immersion compared with on the ground. Masumoto et al. (2004) reported that the individuals walking in the liquid medium showed a decrease in the muscle electrical activity compared with walking on the ground. The authors explained that these results could be attributed to the effect of buoyancy in the water, suggesting that the individuals minimized their efforts to walk in water, which would have resulted in reduced muscular endurance.

According to Pöyhönen et al. (1999) and Kelly et al. (2000), the reduction of muscle electrical activity during immersion exercises can be attributed to the absence of gravity on muscle spindles and proprioceptive receptors in the displacer due to buoyancy.

Another factor that may decrease the electromyographic signal is the water temperature. This study used immersion at $34^{\circ} \mathrm{C}$, which is commonly used in therapeutic pools. It is known that the heated water temperature contributes to muscle relaxation (Biasoli and Machado, 2006) and increased blood supply to the skeletal muscle system by peripheral vasodilation (Becker, 2009; Biasoli and Machado, 2006; Rahmann et al., 2009).

Cuesta-Vargas et al. (2013a) found increased electrical activity of some muscles of the legs on the ground compared with in water; however, when evaluating the trunk muscles, there was a larger increase in the electromyographic signal in the aquatic environment. Müller et al. (2005) also found an increase in the electrical activity of the trunk muscles during immersion in water compared with on the ground, both at standard speed and full speed.

In contrast with the results obtained in this study, Pinto et al. (2010) found no significant changes in the electromyographic activity on land or in water during maximal voluntary isometric contractions of the biceps muscles, triceps brachii, rectus femoris and biceps femoris.

For a study to be comparable on land and in water, playback is needed the same procedure in these two environments, as well as the use of adequate protection to prevent water from entering the electrode during immersion (Castillo-Lozano and Cuesta-Vargas, 2013; Cuesta-Vargas, 2013b). If there is water contact with the electrode during myoelectric evaluation, the myoelectric signal may be decreased (Carvalho et al., 2010; Pöyhönen et al., 1999). In the research conducted, the same procedures on land and in water were made. Furthermore, to evaluate the electromyographic signal in water, water impermeable occlusive tape was used under the electrodes, as well as plastic polyvinyl chloride (PVC) in the region of the body part in question.

Considering the resistance exercises, Pinto et al. (2014) found that when endurance was used before aerobic exercise, there might be optimization of muscle strength and hypertrophy of the lower limbs. Another study investigated the effects of a ten-week training program with progressively increasing resistance in the aquatic environment and evaluated the flexors and knee extensors of twenty-four healthy women. There was a significant increase in the torque, lean mass and neural activation of the muscles, concluding that training in the aquatic environment could be recommended for neuromuscular conditioning (Pöyhönen et al., 2002).

In a therapeutic context, authors report that aquatic therapy allows active movement in the early postoperative period without compromising patient safety (Kelly et al., 2000). According to Bressel et al. (2012), patients with pain symptoms can more easily perform muscle exercises first in an aquatic environment such that that they could be subsequently transferred to the terrestrial environment. Orselli and Duarte (2011) observed a significant reduction in the joint torque during marching in water compared with on land, suggesting that the therapeutic pool is a safe environment for the exercise due to the reduction of impact.

The results of this study are in accordance with most of the ongoing research in the literature, although these studies were performed during exercise without load. The heated water may have contributed to the reduction of electromyographic activity. Some studies reported increased electromyographic activity during exercise in immersion compared with on the ground; however, the analysis was performed on trunk muscles. Therefore, it is suggested to compare the electrical signal of muscles from the same body segment. 
Knowing that there is a reduction of electrical muscle activity while performing movements in the aquatic environment compared with on land, including load use, it is believed that resistance exercises can be performed early in a therapy pool, which will favor the prevention and treatment of musculoskeletal disorders, considering that the patient can sooner return to their activities of daily living.

Future studies on exercises using different resistance graduations performed in other positions and velocities and in a pool with water lower temperature may be conducted to improve the results obtained in this study in order to determine the influence of all of these factors on the electrical activity muscle.

\section{References}

Batterham SI, Heywood S, Keating JL. Systematic review and meta-analysis comparing land and aquatic exercise for people with hip or knee arthritis on function, mobility and other health outcomes. BMC Musculoskeletal Disorders. 2011; 12(1):123. http://dx.doi.org/10.1186/1471-2474-12123. PMid:21635746

Becker BE. Aquatic therapy: scientific foundations and clinical rehabilitation applications. PM \& R. 2009; 1(9):859-72. http:// dx.doi.org/10.1016/j.pmrj.2009.05.017. PMid:19769921

Biasoli MC, Machado CMC. Hidroterapia: técnicas e aplicabilidades clínicas nas disfunções reumatológicas. Revista Brasileira de Medicina. 2006; 63:79-80.

Bressel E, Dolny DG, Vandenberg C, Cronin JB. Trunk muscle activity during spine stabilization exercises performed in a pool. Physical therapy in sport : official journal of the Association of Chartered Physiotherapists in Sports Medicine. 2012; 13(2):67-72. http://dx.doi.org/10.1016/j. ptsp.2011.06.002. PMid:22498146

Cardoso JR, Sousa LB, Lopes LG. Proposta de manual de aplicação do biofeedback eletromiográfico modelo Pathway MR-20 no músculo tibial anterior de pacientes portadores de sequela de Acidente Vascular Cerebral (AVC). Arquivos de Ciências da Saúde da Unipar. 2003; 7:77-82.

Caromano FA, Nowotny JP. Princípios físicos que fundamentam a hidroterapia. Fisioterapia Brasil. 2002; 3:1-9.

Carvalho RGS, Amorim CF, Perácio LHR, Coelho HF, Vieira AC, Karl Menzel HJ, Szmuchrowski LA. Analysis of various conditions in order to measure electromyography of isometric contractions in water and on air. Journal of electromyography and kinesiology : official journal of the International Society of Electrophysiological Kinesiology. 2010; 20(5):988-93. http://dx.doi.org/10.1016/j.jelekin.2009.12.002. PMid:20385505

Castillo-Lozano R, Cuesta-Vargas AI. A comparison land-water environment of maximal voluntary isometric contraction during manual muscle testing through surface electromyography. BMC Sports Science. Medicine and Rehabilitation. 2013; 5:28.
Cuesta-Vargas AI, Cano-Herrera C, Formosa D, Burkett B. Electromyographic responses during time get up and go test in water (wTUG). SpringerPlus. 2013b; 2(1):217. http://dx.doi.org/10.1186/2193-1801-2-217. PMid:23705108

Cuesta-Vargas AI, Cano-Herrera CL, Heywood S. Analysis of the neuromuscular activity during rising from a chair in water and on dry land. Journal of Electromyography and Kinesiology : Official Journal of The International Society of Electrophysiological Kinesiology. 2013a; 23(6):1446-50. http:// dx.doi.org/10.1016/j.jelekin.2013.06.001. PMid:23834813

Devereux K, Robertson D, Briffa NK. Effects of a waterbased program on women 65 years and over: a randomised controlled trial. The Australian Journal of Physiotherapy. 2005; 51(2):102-8. http://dx.doi.org/10.1016/S00049514(05)70038-6. PMid:15924512

Escamilla RF, Fleisig GS, Zheng N, Barrentine SW, Wilk $\mathrm{KE}$, Andrews JR. Biomechanics of the knee during closed kinetic chain and open kinetic chain exercises. Medicine and Science in Sports and Exercise. 1998; 30(4):556-69. http://dx.doi.org/10.1097/00005768-199804000-00014. PMid:9565938

Fujisawa H, Suenaga N, Minami A. Electromyographic study during isometric exercise of the shoulder in head-out water immersion. Journal of Shoulder and Elbow Surgery / American Shoulder and Elbow Surgeons ... [et al.]. 1998; 7(5):491-4. http://dx.doi.org/10.1016/S1058-2746(98)902002. PMid:9814928

Harrison RA, Hillman M, Bulstrode S. Loading of the lower limb when walking partially immersed: implications for clinical practice. Physiotherapy. 1992; 78(3):164-6. http:// dx.doi.org/10.1016/S0031-9406(10)61377-6.

Kelly BT, Roskin LA, Kirkendall DT, Speer KP. Shoulder muscle activation during aquatic and dry land exercises in nonimpaired subjects. The Journal of Orthopaedic and Sports Physical Therapy. 2000; 30(4):204-10. http://dx.doi. org/10.2519/jospt.2000.30.4.204. PMid:10778797

Kisner C, Colby L. Exercícios terapêuticos: fundamentos e técnicas. São Paulo: Manole; 2000.

Masumoto K, Takasugi S, Hotta N, Fujishima K, Iwamoto Y. Electromyographic analysis of walking in water in healthy humans. Journal of Physiological Anthropology and Applied Human Science. 2004; 23(4):119-27. http:// dx.doi.org/10.2114/jpa.23.119. PMid:15314269

Müller ESM, Black GL, Figueiredo PP, Kruel LFM, Hanisch C, Appell HJ. Comparação eletromiográfica do exercício abdominal dentro e fora da água. Revista Portuguesa de Ciências do Desporto. 2005; 5:255-65.

Orselli MIV, Duarte M. Joint forces and torques when walking in shallow water. Journal of Biomechanics. 2011; 44(6):1170-5. http://dx.doi.org/10.1016/j.jbiomech.2011.01.017. PMid:21334630

Pinto SS, Cadore EL, Alberton CL, Zaffari P, Bagatini NC, Baroni BM, Radaelli R, Lanferdini FJ, Colado JC, Pinto RS, Vaz MA, Bottaro M, Kruel LF. Effects of intra-session exercise sequence during water-based concurrent training. International Journal of Sports Medicine. 2014; 35(1):41-8. PMid:23771835. 
Pinto SS, Liedtke GV, Alberton CL, da Silva EM, Cadore EL, Kruel LF. Electromyographic signal and force comparisons during maximal voluntary isometric contraction in water and on dry land. European Journal of Applied Physiology. 2010; 110(5):1075-82. http://dx.doi.org/10.1007/s00421010-1598-0. PMid:20697905

Pöyhönen T, Keskinen KL, Hautala A, Savolainen J, Mälkiä E. Human isometric force production and electromyogram activity of knee extensor muscles in water and on dry land. European Journal of Applied Physiology and Occupational Physiology. 1999; 80(1):52-6. http://dx.doi.org/10.1007/ s004210050557. PMid:10367723

Pöyhönen T, Sipilä S, Keskinen KL, Hautala A, Savolainen J, Mälkiä E. Effects of aquatic resistance training on neuromuscular performance in healthy women. Medicine and Science in Sports and Exercise. 2002; 34(12):2103-9. http://dx.doi.org/10.1097/00005768-200212000-00036. PMid:12471323

Rahmann AE, Brauer SG, Nitz JC. A specific inpatient aquatic physiotherapy program improves strength after total hip or knee replacement surgery: a randomized controlled trial. Archives of Physical Medicine and Rehabilitation. 2009; 90(5):745-55. http://dx.doi.org/10.1016/j.apmr.2008.12.011. PMid:19406293

Roper JA, Bressel E, Tillman MD. Acute aquatic treadmill exercise improves gait and pain in people with knee osteoarthritis. Archives of Physical Medicine and Rehabilitation. 2013; 94(3):419-25. http://dx.doi.org/10.1016/j.apmr.2012.10.027. PMid:23131526

Sugajima Y, Mitarai G, Koeda M, Moritani T. Characteristic changes of motor unit activity in hip joint flexor muscles during voluntary isometric contraction during water immersion. Characteristic Changes of Motor Unit Activity in Hip Joint Flexor Muscles During Voluntary Isometric Contraction During Water Immersion. 1996; 6(2):83-95. http://dx.doi. org/10.1016/1050-6411(95)00020-8. PMid:20719666

Vodusek DB. Electromyography. In: Bo K, Berghmans B, Morkved S, Van Kampen M, editors. Evidence based physical therapy for the pelvic floor. Philadelphia: Elsevier; 2007. p. 53-63.

\footnotetext{
Authors

Indira Nayra Paz Santos ${ }^{1}$, Izabela dos Santos Mendes ${ }^{1}$, Mario Oliveira Lima ${ }^{1}$, Alderico Rodrigues de Paula Junior ${ }^{1}$, Andreza Ribeiro Simioni' ${ }^{2}$, Paulo Roberto Garcia Lucareli ${ }^{3}$ Fernanda Pupio Silva Lima ${ }^{1 *}$

${ }^{1}$ Laboratório de Reabilitação Sensório Motora, Instituto de Pesquisa e Desenvolvimento - IP\&D, Universidade do Vale do Paraíba - Univap, Av. Shishima Hifumi, 2911, CEP 12244-000, Urbanova, São José dos Campos, SP, Brazil.

${ }^{2}$ Laboratório de Síntese Orgânica - IP\&D, Universidade do Vale do Paraíba - Univap, São José dos Campos, SP, Brazil.

${ }^{3}$ Laboratório de Estudos do Movimento, Universidade Nove de Julho - Uninove, São José dos Campos, SP, Brazil.
} 